\title{
Optimizing the Selection of Cost Drivers in Activity-Based Costing Using Quasi-Knapsack Structure
}

\author{
Saleem Zeyad Ramadan ${ }^{1}$ \\ ${ }^{1}$ Dept. of Mechanical and Industrial Engineering, Applied Science Private University, Amman, Jordan \\ Correspondence: Saleem Zeyad Ramadan, Dept. of Mechanical and Industrial Engineering, Applied Science \\ Private University, Amman, Jordan. E-mail: s_ramadan@asu.edu.jo
}

Received: February 18, 2015

Accepted: June 4, 2015

Online Published: June 20, 2015

doi:10.5539/ijbm.v10n7p74

URL: http://dx.doi.org/10.5539/ijbm.v10n7p74

\begin{abstract}
In this article, we are presenting a model for optimizing the selection of cost drivers in activity-based costing such that the optimal set of cost drivers will minimize the sum of the absolute product unit price deviations and will keep the budget under the intended amount utilizing a quasi-Knapsack structure. Comparative analysis from two benchmark problems showed the effectiveness of the proposed model. Moreover, the comparative analysis showed that categorizing the cost drivers into four operational expenses levels as suggested by cooper and Kaplan (1991) did not always lead to a better solution. Furthermore, the study showed that the budget is not the only determinant that determines the best set of cost drivers, the way that the expenses of the removed cost drivers are handled is also a determinant for the effectiveness of the model.
\end{abstract}

Keywords: activity-based costing, quasi-knapsack problem, cost driver optimization, CDO model

\section{Introduction}

Traditionally, manufacturing overhead cost is allocated based on plantwide rate such as machine hours or direct labor (Brignall, 1997). In case of high value of overhead cost relative to direct cost value or in case that the overhead allocation is not based on volume, traditional costing system may allocates the overhead cost to the products inaccurately (Baird et al., 2004). Furthermore, the traditional costing system suffers from the problem of non-homogenous cost pools that contain a collection of costs with different reasons. As a consequence of these short comes, inaccurate product pricing occurs that is manifested in direct loss in case of under pricing the product or the form of market share loss in case of overpricing the product. In either case, this can have devastated consequences on the company. The remedy for these devastated consequences is in adapting more effective management costing system such as Activity-Based Costing (ABC) system, which characterized by a homogenous cost pools as all costs that have the same reason are gathered in the same cost pool, thus cost allocation is based on cost causatives. Moreover, the ABC system allocates costs using number of operational expenses levels against usually one plantwide level in the traditional costing system, the matter that increases the information accuracy obtained by the ABC analysis (Foster \& Swenson, 1997; McGowan \& Klammer, 1997).

Unfortunately, the attempt of increasing the information accuracy by increasing the number of cost drivers in $\mathrm{ABC}$ analysis usually associated with increasing the analysis cost. Cooper, 1989 drew the attention to this dilemma by calling for proper choice of cost drivers number and type used in $\mathrm{ABC}$ analysis. Later on, he but a frame work to deal with this dilemma and suggested that the number of cost drivers used in ABC analysis should be increased as the cost objects mixed become more diverse. He also drew the attention that small and/or correlated cost activities should not have a separate cost drivers and they should be combined with other cost drivers. These notes lay the foundation for what is known in literature as Cost Drivers Optimization (CDO) problem. Lately many authors emphasized the importance of cost drivers and the role that they play as a main difference between the traditional and ABC costing systems like (Geri \& Ronen, 2005; Oduoza, 2009; Cokins \& Căpuşneanu, 2010). In 1993, Babad, and Balachandran proposed the first mathematical model to solve the CDO problem. In their paper, they developed a CDO model that compromise between the accuracy of information cost and the information-gathering cost using Greedy algorithm. Later on, Alan and Gupta, 1996 developed a Genetic Algorithm (GA) for solving the CDO problem based on Babad, and Balachandran, (1993) model. Casten (2001) used Babad and Balachandran, 1993 model to solve the CDO problem but instead of replacing the cost driver with only one other cost driver, he considered replacing the cost driver with a combination of cost drivers. Datar 
et al., 1993 used the simultaneous equation method to solve the CDO problem for U.S. firm. Banker et al. (1995), Duh et al. (2009), and Wang et al. (2010) investigated the application of linear regression analysis to the CDO problem for different companies.

The core of all these methods for solving the CDO problem is to have a compromise between the cost of performing the $\mathrm{ABC}$ analysis and the accuracy obtained from this analysis. In general, the more the accuracy the $\mathrm{ABC}$ system provides, the higher the cost of that system. This is true because, the higher the accuracy needed, the higher the number of cost drivers needed and thus the higher the information-gathering cost needed. For this reason, the $\mathrm{CDO}$ problem concerns with finding the best number of cost drivers along with which cost drivers are needed to maximize the precision resulted from the analysis while keeping the cost of analysis within budget. Unfortunately, most of the CDO models neglected the budget as a separate constraint and incorporated it in the objective function. In this study, a model for solving CDO problem is proposed to find the optimal cost drivers that minimize the sum of the absolute deviations between the ideal unit product cost (using all the cost drivers available) and the unit product cost (using the optimal set of cost drivers) using a quasi-Knapsack structure under budget constraint. This model will find a trade-off between the efficiency and the effectiveness of the cost drivers used in the $\mathrm{ABC}$ analysis. The objective function of this proposed model differs than the one used in Babad, and Balachandran, the one that many authors adopt in a way or another for solving the CDO problem, in that this objective function takes into consideration the effectiveness of the analysis (minimum absolute error) while having the efficiency (budget) of the analysis as a constraint. Moreover, this model allocates the expenses of the unused cost drivers to the optimal set of cost drivers based on their expenses proportions. Furthermore, this model can be used to determine the optimal plantwide cost driver for the traditional costing system if desired by the decision maker.

For sake of completion, this model will be extended to take into consideration the four levels of operating expenses suggested by cooper and Kaplan (1991) to see what impact of categorizing cost drivers into these operating expenses have on the accuracy of the model.

The rest of the paper will be organized as follows: section 2 will define the variables used in the proposed model, section 3 will present the proposed model, section 4 will solve two benchmark examples adapted from literature for comparative analysis, section 5 will extend the model to accommodate for the four operating expenses suggested by cooper and Kaplan (1991), and section 6 will summarize the findings.

\section{Model Derivation}

For our model, $\mathbf{P}$ denotes a vector of products or cost objects such that $p \in \mathbf{P}$ is the $p^{\text {th }}$ product in $\mathbf{P}, \mathbf{J}$ denotes a vector of cost drivers for production or service activities such that $j \in \mathbf{J}$ is the $j^{\text {th }}$ cost driver in $\mathbf{J}$, and $\mathbf{R}$ denotes a vector containing the indices of the removed cost drivers from $\mathbf{J}$.

let us define the following:

$Q_{p j}$ : The quantity of $j^{\text {th }}$ cost driver used by the $p^{\text {th }}$ product.

$A_{j}$ : The expense of the $j^{\text {th }}$ cost driver.

$\dot{A}_{j}$ : The expense of the $j^{t h}$ cost driver after adding its share expenses from all other removed cost drivers $r \in \mathbf{R}$ expenses:

$$
\dot{A}_{j \notin R}=\left(\sum_{j \in R} A_{j}\right) \times \frac{A_{j \notin R}}{\sum_{j \notin R} A_{j}}+A_{j \notin R},
$$

$x_{j}$ : A binary indicator variable that indicates whether the $j^{\text {th }}$ cost driver is included in the optimal solution or not such that:

$$
x_{j}=\left\{\begin{array}{l}
1 \mathrm{j} \neq \mathrm{r} \\
0 \mathrm{j}=\mathrm{r}
\end{array}\right\}
$$

$\dot{A}_{j}$ can be rewritten using $x_{j}$ as follows:

$$
\dot{A}_{j}=\left[\sum_{j} A_{j}\left(1-x_{j}\right)\right] \times \frac{A_{j} x_{j}}{\sum_{j} A_{j} x_{j}}+A_{j} x_{j} .
$$

$U_{p}$ : Number of units produced from the $p^{\text {th }}$ product.

$C_{p}^{*}$ : The ideal total cost of the $p^{\text {th }}$ product using all cost drivers available.

$C_{p}$ : The approximated total cost of the $p^{\text {th }}$ product using the optimal set of cost drivers. 
$U P_{p}^{*}$ : The ideal unit cost of the $p^{\text {th }}$ product using all cost drivers available.

$U P_{p}$ : The approximated unit cost of the $p^{\text {th }}$ product using the updated set of cost drivers.

From these definitions it should be clear that:

$$
U P_{p}^{*}=\frac{C_{p}^{*}}{U_{p}}
$$

And,

$$
U P_{p}=\frac{C_{p}}{U_{p}},
$$

Where:

$$
C_{p}^{*}=\sum_{j}\left[A_{j} \times \frac{Q_{p j}}{\sum_{p} Q_{p j}}\right]
$$

and

$$
C_{p}=\sum_{j \notin R}\left[\dot{A}_{j} \times \frac{Q_{p j}}{\sum_{p} Q_{p j}}\right]
$$

This means that

$$
U P_{p}^{*}=\frac{\sum_{j}\left[A_{j} \times \frac{Q_{p j}}{\sum_{p} Q_{p j}}\right]}{U_{p}}
$$

and

$$
U P_{p}=\frac{\sum_{j \notin R}\left[\dot{A}_{j} \times \frac{Q_{p j}}{\sum p Q_{p j}}\right]}{U_{p}} .
$$

In this study, the objective function of the proposed model will minimize the sum of the absolute deviations between the ideal unit cost of the $p^{\text {th }}$ product using all cost drivers available and the unit cost of the $p^{\text {th }}$ product using the updated set of cost drivers. Mathematically, this objective function can be given as:

$$
\sum_{P} a b s\left(\frac{\sum_{j}\left[A_{j} \times \frac{Q_{p j}}{\sum p Q_{p j}}\right]}{U_{p}}-\frac{\sum_{j \notin R}\left[\dot{A}_{j} \times \frac{Q_{p j}}{\sum \sum_{p} Q_{p j}}\right]}{U_{p}}\right) .
$$

Alternatively, $U P_{p}$ can be expressed in terms of the binary indicator variable $x_{j}$ as follows:

$$
U P_{p}=\frac{\sum_{j}\left[\dot{A}_{j} \times \frac{Q_{p j}}{\sum p Q_{p j}} x_{j}\right]}{U_{p}},
$$

This means that the objective function can be rewritten as:

$$
\sum_{P} a b s\left(\frac{\sum_{j}\left[A_{j} \times \frac{Q_{p j}}{\sum_{p} Q_{p j}}\right]}{U_{p}}-\frac{\sum_{j}\left[\dot{A}_{j} \times \frac{Q_{p j}}{\sum_{p} Q_{p j}} x_{j}\right]}{U_{p}}\right) .
$$

Furthermore, the objective function can be simplified by combining the two summations as follows:

$$
\sum_{P} a b s\left(\sum_{j}\left[\frac{Q_{p j}}{\frac{\sum_{p} Q_{p j}}{U_{p}}}\left(A_{j}-\dot{A}_{j} x_{j}\right)\right]\right) .
$$

where $\dot{A}_{j} x_{j}$ is:

$$
\dot{A}_{j} x_{j}=\left[\sum_{j} A_{j}\left(1-x_{j}\right)\right] \times \frac{A_{j}}{\sum_{j} A_{j} x_{j}} x_{j}^{2}+A_{j} x_{j}^{2} .
$$

Note that $x_{j}{ }^{2}$ can be replaced with $x_{j}$ since $x_{j}$ is binary and thus the square of its value is the same as the 
original value so we can replace $x_{j}^{2}$ with $x_{j}$ in the objective function.

Taking $A_{j}$ and $x_{j}$ as common factors, the objective function can be further reduces to:

$$
\sum_{P} a b s\left(\sum_{j} \frac{\frac{Q_{p j}}{\sum p Q_{p j}}}{U_{p}} A_{j}\left(1-\left(\frac{\left[\sum_{j} A_{j}\left(1-x_{j}\right)\right]}{\sum_{j} A_{j} x_{j}}+1\right) x_{j}\right)\right) .
$$

This function is not a linear function and hence the name quasi-Knapsack is used. This function represents the deviation between the ideal unit price and the expected unit price and thus it represents the error introduced because of removing some of the cost drivers. This error must be minimized and hence the overall objective function is as follows:

$$
\min \sum_{P} a b s\left(\sum_{j} \frac{\frac{Q_{p j}}{\sum p Q_{p j}}}{U_{p}} A_{j}\left(1-\left(\frac{\left[\sum_{j} A_{j}\left(1-x_{j}\right)\right]}{\sum_{j} A_{j} x_{j}}+1\right) x_{j}\right)\right) .
$$

This objective function will be minimized under the constraint of budget such that the overall cost of the ABC analysis will not exceed the intended budget. This means that the total cost of gathering-information for the survived cost drivers must not exceed the budget allocated for $\mathrm{ABC}$ analysis. Let

$D_{j}$ : The cost of gathering information (cost of data collection, analysis, and storage) for the $j^{\text {th }}$ cost driver then $\sum_{j} D_{j} x_{j}$ is the total cost for the analysis, hence:

$$
\sum_{j} D_{j} x_{j} \leq \text { budget. }
$$

Moreover, the minimum cost of gathering information about the cost drivers must not exceed the budget allocated for the $\mathrm{ABC}$ analysis. This can be seen as a feasibility check whether the budget is enough to carry out the minimal requirement of the $\mathrm{ABC}$ analysis with at least one cost driver or not. This is a feasibility check because if this value is more than the budget available to carry out the $\mathrm{ABC}$ analysis, there is no way to perform this analysis. This requirement can be expressed mathematically as:

$$
\min \left(D_{j}\right) \leq \text { Budget. }
$$

Furthermore the number of cost drivers survived must be at least one to meet the minimum requirement of performing any cost analysis. If the number of survived cost drivers is one, then the analysis will be equivalent to the traditional costing system analysis. This constraint can be expressed mathematically as:

$$
\sum_{j} x_{j} \geq 1 \text {. }
$$

\subsection{The Full Proposed Model}

The mathematical formulation of the $\mathrm{CDO}$ problem proposed in this study is as follows:

$$
\min \sum_{P} a b s\left(\sum_{j} \frac{\frac{Q_{p j}}{\sum_{p} Q_{p j}}}{U_{p}} A_{j}\left(1-\left(\frac{\left[\sum_{j} A_{j}\left(1-x_{j}\right)\right]}{\sum_{j} A_{j} x_{j}}+1\right) x_{j}\right)\right),
$$

s.t

$$
\begin{gathered}
\min \left(D_{j}\right) \leq \text { Budget }, \\
\sum_{j} D_{j} x_{j} \leq \text { budget }, \\
\sum_{j} x_{j} \geq 1, \\
x_{j} \text { binary. }
\end{gathered}
$$

Equation $\mathrm{A} 1$ is the objective function that calculates and minimizes the total absolute unit-price error in the analysis. Equation A2 guarantees that there is enough money to carry out the minimal requirement of the ABC analysis. Equation A3 guarantees that the total cost for the optimal solution will not exceed the required budget for the analysis. Equation A4 guarantees that at least one cost driver will be selected. If this inequality in this constraint changed to equality with 1 then this model will find the best plantwide cost driver for the traditional costing. 


\section{Illustrative Examples and Results}

To illustrate the proposed model, two examples will be used. The first example is adapted from Smith and Leksan (1991) and the second example is adapted from Babad and Balachandran (1993). These examples will be solved using the proposed model. For convenience, the relevant data for these examples will be repeated in this paper.

\section{Example 1}

The first example is adapted from smith and Leksan (1991) where three products and ten cost drivers are originally used in their analysis. Table 1 shows the relevant data for this example. This example was solved twice in Levitan and Gupta (1996) using the model proposed by Babad, and Balachandran (1993): the first time it was solved using Greedy method and the second time using GA method. For comparison purposes, the example will be solved using our model with a budget of $\$ 3,300$ to compare its performance with Greedy and GA solutions. The beauty of this model is in its simplicity where it can be solved easily using Excel Solver.

Table 1. Production cost data adapted from smith and Leksan, 1991

\begin{tabular}{|c|c|c|c|c|c|c|c|c|c|c|c|}
\hline Product & Quantity & $\begin{array}{l}\text { Purchasing } \\
\text { material } \\
\text { (D1) }\end{array}$ & $\begin{array}{l}\text { Purchasing } \\
\text { Components } \\
\text { (D2) }\end{array}$ & $\begin{array}{l}\text { Number } \\
\text { of } \\
\text { Vendors } \\
\text { (D3) }\end{array}$ & $\begin{array}{l}\text { Number } \\
\text { of units } \\
\text { (D4) }\end{array}$ & $\begin{array}{l}\text { Units } \\
\text { expedited } \\
\text { (D5) }\end{array}$ & $\begin{array}{l}\text { Part } \\
\text { Shipments } \\
\text { (D6) }\end{array}$ & $\begin{array}{l}\text { Material } \\
\text { shipments } \\
\text { (D7) }\end{array}$ & $\begin{array}{l}\text { Production } \\
\text { runs (D8) }\end{array}$ & $\begin{array}{l}\text { Total } \\
\text { shipments } \\
\text { (D9) }\end{array}$ & $\begin{array}{l}\text { Inspection } \\
\text { points } \\
\text { (D10) }\end{array}$ \\
\hline P C & 7000 & 500 & 2000 & 25 & 7000 & 1500 & 2000 & 500 & 10 & 2500 & 196000 \\
\hline $\mathrm{PM}$ & 2900 & 300 & 1500 & 30 & 2900 & 450 & 1500 & 300 & 15 & 1800 & 118900 \\
\hline PL & 100 & 200 & 500 & 45 & 100 & 50 & 500 & 200 & 25 & 700 & 5100 \\
\hline Units consumed (\#) & & 1000 & 4000 & 100 & 10000 & 2000 & 4000 & 1000 & 50 & 5000 & 320000 \\
\hline Dollar value (\$) & & 2000 & 1000 & 2000 & 2000 & 1000 & 5000 & 2500 & 2500 & 3000 & 4000 \\
\hline Information cost (\$) & & 1500 & 1800 & 1700 & 1800 & 2000 & 1800 & 2200 & 2300 & 2400 & 1700 \\
\hline
\end{tabular}

Using Excel 2007 Solver, the proposed model suggests using Purchasing material and Purchasing components cost drivers as the key cost drivers. Using these optimal cost drivers, the product unit cost calculations are as follows:

The new expenses of the $\mathrm{D}_{1}$ and $\mathrm{D}_{2}$ cost drivers $\left(\dot{A}_{1}, \dot{A}_{2}\right)$ after adding their shares from the expenses of the removed cost drivers $\left(\mathrm{D}_{3}, \mathrm{D}_{4}, \mathrm{D}_{5}, \mathrm{D}_{6}, \mathrm{D}_{7}, \mathrm{D}_{8}, \mathrm{D}_{9}, \mathrm{D}_{10}\right)$ are:

$$
\dot{A}_{1}=22000 \times \frac{2000}{3000}+2000=16666.66
$$

and

$$
\dot{A}_{2}=22000 \times \frac{1000}{3000}+1000=8333.33,
$$

Respectively. Table 2 shows the rest of the $\mathrm{ABC}$ analysis calculations for the unit costs of the three products based on the optimal set of cost drivers; Purchasing material and Purchasing components.

Table 2. ABC analysis calculations based on the optimal set of cost drivers

\begin{tabular}{|c|c|c|c|c|c|c|c|}
\hline & $\begin{array}{l}\text { Activity cost } \\
\text { driver rate }\end{array}$ & ACDQ P1 & $\begin{array}{l}\text { Activity } \\
\text { expense P1 }\end{array}$ & ACDQ P2 & $\begin{array}{l}\text { Activity } \\
\text { expense P2 }\end{array}$ & ACDQ P3 & $\begin{array}{l}\text { Activity } \\
\text { expense P3 }\end{array}$ \\
\hline Purchasing material & $\begin{array}{l}\$ 16.66 \text { per } \$ \text { of } \\
\text { purchased }\end{array}$ & 500 & $\$ 8333.3$ & 300 & $\$ 5000$ & 200 & $\$ 3333.3$ \\
\hline
\end{tabular}

\begin{tabular}{lllll}
\hline Activity & Activity expense & Activity cost driver & Activity cost driver quantity & Activity cost driver rate \\
\hline Purchasing material & $\$ 16666.66$ & $\$$ of purchased material & 1000 & $\$ 16.66$ per $\$$ of purchased material \\
Purchasing components & $\$ 8333.33$ & $\$$ of purchased components & 4000 & $\$ 2.083$ per component \\
\hline
\end{tabular}




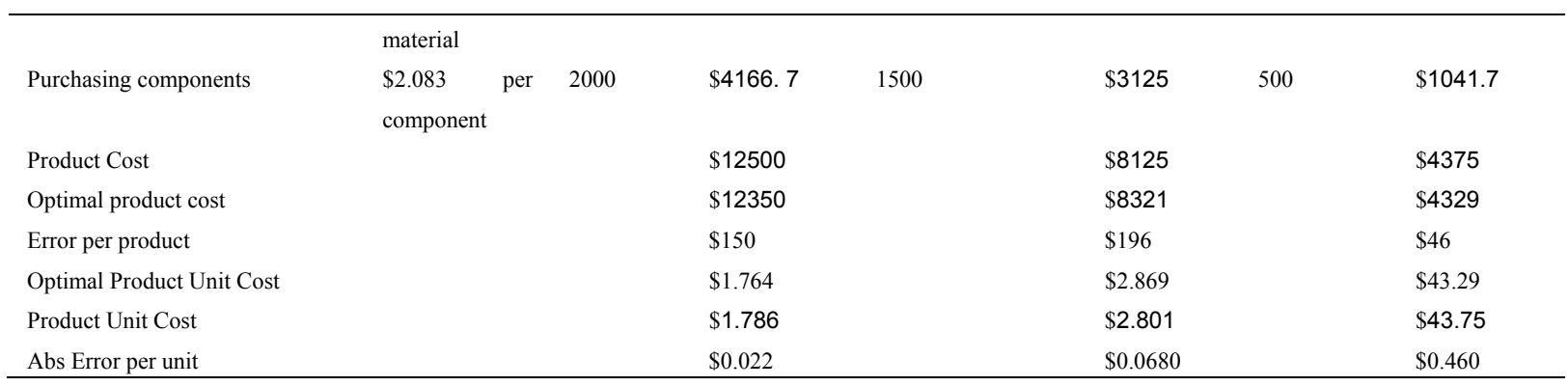

Table 3 shows a comparison between the proposed model results and Greedy and GA results.

Table 3. Comparative analysis between the proposed model, Greedy, and GA for example 1

\begin{tabular}{|c|c|c|c|c|c|c|c|c|}
\hline & $\begin{array}{l}\text { Optimal } \\
\text { cost }\end{array}$ & $\begin{array}{l}\text { Unit cost } \\
\text { (\$/unit) }\end{array}$ & & & $\begin{array}{l}\text { Budget } \\
\text { (\$) }\end{array}$ & $\begin{array}{l}\text { Cost } \\
\text { Savings } \\
(\$)\end{array}$ & $\begin{array}{l}\text { Objective } \\
\text { Function } \\
\text { (\$/unit) }\end{array}$ & $\begin{array}{l}\text { Absolute } \\
\text { total cost } \\
\text { deviation } \\
(\$)\end{array}$ \\
\hline Solved By & driver set & $\mathrm{P} 1$ & $\mathrm{P} 2$ & $\mathrm{P} 3$ & & & & \\
\hline Ideal using all cost drivers & All ten & 1.764 & 2.869 & 43.288 & 19200 & 0 & 0 & 0 \\
\hline Babad, and Balachandran, 1993 (Greedy) & N/A & 1.825 & 2.769 & 41.950 & 6800 & 12400 & 1.499 & 850 \\
\hline Levitan and Gupta, 1996 (GA) & D1, D6 & 1.786 & 2.935 & 39.880 & 3300 & 15900 & 3.495 & 681 \\
\hline Proposed model@ @udget $\$ 3300$ & D1, D2 & 1.786 & 2.801 & 43.750 & 3300 & 15900 & 0.55 & 392 \\
\hline
\end{tabular}

Table 3 shows that the proposed model has a better objective function value (0.55) than Greedy and GA methods (1.499 and 3.495, respectively) as it has a more precise product unit costs $(1.786,2.801,43.750)$ than Greedy and GA methods $(\{1.825,2.769,41.950\},\{1.786,2.935,39.880\}$, respectively). Moreover, the proposed model has a cost savings of $\$ 15,900$, which is better than $\$ 12,400$ cost savings found by Greedy method and has the same cost savings found in GA. Furthermore, the absolute total cost deviation for the proposed model was $\$ 392$ which is better than $\$ 850$ and $\$ 681$ for Greedy and GA methods, respectively.

\section{Example 2}

The second example is adapted from Babad, and Balachandran, 1993 where four products and seven cost drivers are originally used in their analysis. Table 4 shows the relevant data for this example. This example was solved twice in Levitan and Gupta, 1996 using Greedy and GA methods. For comparison purposes, the example will be solved using our model with a budget of $\$ 2,000$ to compare its performance with Greedy and GA solutions.

Table 4. Production cost data adapted from Babad, and Balachandran, 1993

\begin{tabular}{|c|c|c|c|c|c|c|c|c|c|c|c|c|}
\hline Product & Quantity & $\begin{array}{l}\text { Material } \\
\text { (D1) }\end{array}$ & (dollars) & $\begin{array}{l}\text { Direct } \\
\text { (D2) }\end{array}$ & labor & $\begin{array}{l}\text { Machine } \\
\text { (D3) }\end{array}$ & hours & $\begin{array}{l}\text { Setups } \\
\text { (D4) }\end{array}$ & $\begin{array}{l}\text { Orders } \\
\text { (D5) }\end{array}$ & $\begin{array}{l}\text { Times } \\
\text { (D6) }\end{array}$ & handled & $\begin{array}{l}\text { Parts } \\
\text { (D7) }\end{array}$ \\
\hline $\mathrm{P} 1$ & 10 & 60 & & 5 & & 10 & & 1 & 1 & 1 & & 1 \\
\hline $\mathrm{P} 2$ & 100 & 600 & & 50 & & 40 & & 2 & 3 & 3 & & 1 \\
\hline P3 & 10 & 180 & & 15 & & 20 & & 1 & 1 & 1 & & 1 \\
\hline P4 & 100 & 1800 & & 150 & & 100 & & 4 & 3 & 3 & & 1 \\
\hline Units consumed (\#) & & 2640 & & 220 & & 170 & & 8 & 8 & 8 & & 4 \\
\hline Dollar value (\$) & & 264 & & 220 & & 3400 & & 960 & 1000 & 200 & & 2000 \\
\hline Information cost (\$) & & & & 2500 & & 1500 & & 2000 & 2000 & & & 2500 \\
\hline
\end{tabular}

Using Excel 2007 Solver, the proposed model suggests using Material, Setups, and Times handled cost drivers as the key cost drivers. Table 5 shows a comparison between the proposed model results and Greedy and GA results using these optimal cost drivers. 
Table 5. Comparative analysis between the proposed model, greedy, and GA for example 2

\begin{tabular}{|c|c|c|c|c|c|c|c|c|c|}
\hline \multirow[b]{2}{*}{ Solved By } & \multirow{2}{*}{$\begin{array}{l}\text { Optimal cost } \\
\text { driver set }\end{array}$} & \multicolumn{4}{|c|}{ Unit price (\$/unit) } & \multirow[t]{2}{*}{$\begin{array}{l}\text { Budget } \\
(\$)\end{array}$} & \multirow[t]{2}{*}{$\begin{array}{l}\text { Cost } \\
\text { Savings } \\
(\$)\end{array}$} & \multirow[t]{2}{*}{$\begin{array}{l}\text { Objective } \\
\text { Function } \\
\text { (\$/unit) }\end{array}$} & \multirow[t]{2}{*}{$\begin{array}{l}\text { Absolute } \\
\text { total cost } \\
\text { deviation } \\
(\$)\end{array}$} \\
\hline & & $\mathrm{P} 1$ & $\mathrm{P} 2$ & P3 & $\mathrm{P} 4$ & & & & \\
\hline Ideal using all cost drivers & All seven & 102.6 & 25.5 & 133.8 & 51.1 & 10500 & 0 & 0 & 0 \\
\hline Babad, and Balachandran, 1993 (Greedy) & D3, D5 & 80.14 & 28.06 & 120.28 & 52.14 & 3500 & 7000 & 39.62 & 720 \\
\hline Levitan and Gupta, 1996 (GA) & D4 & 125.3 & 25.06 & 125.3 & 50.12 & 2000 & 8500 & 32.62 & 454 \\
\hline Proposed model @ budget $\$ 2000$ & D1, D4, D6 & 106.29 & 26.4 & 114.74 & 51.74 & 2000 & 8500 & 24.2 & 381 \\
\hline
\end{tabular}

Table 5 shows that the proposed model has a better objective function value (24.2) than Greedy and GA methods (32.62 and 39.62, respectively) as it has more precise product unit values $(106.29,26.4,114.74,51.74)$ than Greedy and GA methods $(\{80.14,28.06,120.28,52.14\},\{125.3,25.06,125.3,50.12\}$, respectively). Moreover, the proposed model has a cost savings of $\$ 8,500$ which is better than $\$ 7,000$ cost savings found by Greedy method and has the same cost savings found in GA. Furthermore, the absolute total cost deviation for the proposed model was $\$ 381$ which is better than $\$ 720$ and $\$ 454$ for Greedy and GA methods, respectively.

For sake of completion, the proposed model was used to determine the optimal plantwide cost driver for traditional costing analysis for the two examples by replacing Equation A4 with:

$$
\sum_{j} x_{j}=1
$$

and solving the model. For example1, the problem has an alternative optima. The plantwide cost driver was either Purchasing material or Material shipments with objective value of 7.02. The cost savings was $\$ 17,700$ for Purchasing material and $\$ 17,000$ for Material shipments. It is obvious that Purchasing material has the same objective function of Material shipments but with lower cost, so Purchasing material should be selected as the plantwide cost driver for this example. For example 2 the plantwide cost driver was the Setups cost driver with objective value 32.62. The cost savings was $\$ 8,500$. Surprisingly, this cost driver was reported in Levitan and Gupta, 1996 using their GA method (See Table 5) as the optimal solution.

\subsection{Model Extension}

The proposed model can be extended easily to take into consideration the four levels of operating expenses (Unit-level, Batch-Level, Product-level, and Facility-level) suggested by cooper and Kaplan (1991) in determining the optimal cost drivers set if desired by the decision maker. This can be easily done by introducing four more constraints, one for each operating expense level. To do so, the set of the original cost drivers must first be categorized into four categories, a category for each operating expense level. This will introduce another index in the variables used in the proposed model in section 3 as follows:

$$
\sum_{P} a b s\left(\frac{\sum_{j} A_{j} \times \frac{Q_{p j}}{\sum_{p} Q_{p j}}}{U_{p}}-\frac{\sum_{L \in O E} \sum_{j \in n_{L}} \dot{A}_{j} \times \frac{Q_{p j}}{\sum p Q_{p j}} x_{j}}{U_{p}}\right)
$$

s.t

$$
\begin{gathered}
\sum_{L \in O E} \min \left(D_{L}\right) \leq \text { Budget }, \\
\sum_{L \in O E} \sum_{j \in n_{L}} D_{j} x_{j} \leq \text { budget }, \\
N_{u} \leq \sum_{j \in n_{u}} x_{j} \leq \operatorname{card}\left(n_{u}\right), \\
N_{b} \leq \sum_{j \in n_{b}} x_{j} \leq \operatorname{card}\left(n_{b}\right), \\
N_{p r} \leq \sum_{j \in n_{p r}} x_{j} \leq \operatorname{card}\left(n_{p r}\right), \\
N_{f} \leq \sum_{j \in n_{f}} x_{j} \leq \operatorname{card}\left(n_{f}\right), \\
x_{j} \text { binary. }
\end{gathered}
$$

where $L$ is an index standing for operating expenses levels, $O E$ is a set of the operating expenses levels: Unit level $u$, Batch level $b$, Product level $p r$, and Facility level $f$. 
Moreover, $D_{L}=\left\{\min _{\mathrm{i} \in n_{u}}\left(D_{i u}\right), \min _{\mathrm{i} \in n_{b}}\left(D_{i b}\right), \min _{\mathrm{i} \in n_{p r}}\left(D_{i p r}\right), \min _{\mathrm{i} \in n_{f}}\left(D_{i f}\right)\right\}, D_{i(.)}$ is the cost of gathering information for the $i^{\text {th }}$ cost driver from the set of the cost drivers belong to the specific operating expense level $\{u, b, p r, f\} . n_{u}, n_{b}, n_{p r}$, and $n_{f}$ are sets including the indices for unit level, batch level, product level, and facility level cost drivers, respectively. $N_{u}, N_{b}, N_{p r}$, and $N_{f}$ are the minimum number of cost drivers required in the analysis from unit, batch, product, and facility operating level expenses, respectively. $\operatorname{card}($.$) is the$ cardinality of the set. These values are obtained from the taxonomy of the operating expenses levels.

$\dot{A}_{j}$ must also be modified to allow for combining cost driver expenses within the same operating expense level only, it can be rewritten as follows:

$$
\dot{A}_{j \in n_{L}}=\left(\sum_{j \in r, r \in n_{L}} A_{j}\right) \times \frac{A_{j \in\left(n_{L}-r\right)}}{\sum_{j \in\left(n_{L}-r\right)} A_{j}}+A_{\left(j \in\left(n_{L}-r\right)\right)}, \forall L \in O E
$$

The two examples discussed in section 4 will be repeated here to compare their results with the results obtained from the extended version of the model.

\section{Example 1}

Table 6 shows the taxonomy of operating expenses levels, the values of $N_{u}, N_{b}, N_{p r}$, and $N_{f}$ will be set to $\{1,1$, $1,1\}$, respectively, to insure that at least one of the cost drivers from each operating expense level is included in the analysis. From Table 6 , the $\operatorname{card}\left(n_{u}\right), \operatorname{card}\left(n_{b}\right), \operatorname{card}\left(n_{p r}\right), \operatorname{card}\left(n_{f}\right)$ are $\{2,2,3,3\}$, respectively. Using Excel 2007 Solver, at $\$ 8000$ budget, the extended model suggested using Number of Vendors, Units Expedited, Total Shipments, Inspection Points cost drivers as the key cost drivers. Table 7 shows a comparison between the proposed model results and extended model results.

Table 6. Taxonomy of operating expenses levels for example 1

\begin{tabular}{ll}
\hline Cost Driver & Operating Expense Level \\
\hline D4, D5 & Unit Level \\
D8, D10 & Batch Level \\
D1, D2, D9 & Product Level \\
D3, D6, D7 & Facility Level \\
\hline
\end{tabular}

Table 7. Comparative analysis between the proposed model and the extended model for example 1

\begin{tabular}{llllllllll}
\hline & & Unit cost & & Budget & Cost & Objective \\
& Optimal cost driver & (\$/unit) & & & $(\$)$ & Savings $(\$)$ & Function $(\$ /$ unit $)$ & deviation $(\$)$ \\
Solved By & set & P1 & P2 & P3 & & & \\
\hline Proposed model @ budget \$8000 & D1, D5, D6, D8 & 1.71 & 3.00 & 43.31 & 7600 & 11600 & 0.22 & \\
Extended model @ budget \$8000 & D3, D5, D9, D10 & 1.90 & 2.47 & 45.45 & 7800 & 11400 & 2.70 & 2308. \\
\hline
\end{tabular}

Table 7 shows that the extended model did not find a better set of cost drivers than the propose model in section 3 . The best set found using the extended model was $\{\mathrm{D} 3, \mathrm{D} 5, \mathrm{D} 9, \mathrm{D} 10\}$ with $\$ 2.70 /$ unit objective function value while the best set for the proposed model $\{\mathrm{D} 1, \mathrm{D} 5, \mathrm{D} 6, \mathrm{D} 8\}$ with $\$ 0.22 /$ unit objective function value. Also the absolute total cost deviation found by the extended model (\$2308) was worse than the one found by the proposed model (\$811.11). It should be noticed here that the proposed model chose cost drivers set that included one cost driver from each level. The difference in the performance between the proposed model and the extended model is a result of the way that the expenses of the removed cost drivers are allocated in both models. This means that the budget is not the only determinant that determines the best set of cost drivers, the way that the expenses of the removed cost drivers are handled is also a determinant for the effectiveness of the model.

\section{Example 2}

Table 8 shows the taxonomy of the operating expenses levels. The values of $N_{u}, N_{b}, N_{p r}$, and $N_{f}$ will be set to $\{1,1,1,1\}$, respectively, to insure that at least one of the cost drivers from each operating expense level is included in the analysis. From Table 8, the $\operatorname{card}\left(n_{u}\right), \operatorname{card}\left(n_{b}\right), \operatorname{card}\left(n_{p r}\right), \operatorname{card}\left(n_{f}\right)$ are $\{3,1,2,1\}$, 
respectively.

Table 8. Taxonomy of operating expenses for example 2

\begin{tabular}{ll}
\hline Cost Driver & Operating Expense Level \\
\hline D1, D2, D3 & Unit Level \\
D4 & Batch Level \\
D5, D6 & Product Level \\
D7 & Facility Level \\
\hline
\end{tabular}

Using Excel 2007, the optimal solution was using Material, Machine hours, Setups, Times handled, and Parts as the optimal cost drivers with a total budget of $\$ 6000$ and an objective function value of $\$ 19.54 /$ unit, while the proposed model in section 3 chose Material, Machine hours, Direct labor, Times handled, and Parts as the optimal cost drivers with a total budget of $\$ 6500$ and an objective function value of $\$ 10.80$ /unit as shown in Table 9. Once again, the proposed model outperformed the extended model in terms of the objective function value while the extended model outperformed the proposed model in the absolute total deviation and budget. The reasons for this performance are the introducing of the four operating expenses levels and the way that the expenses of the removed cost drivers are allocated.

Table 9. Comparative analysis between the proposed model and the extended model for example 2

\begin{tabular}{|c|c|c|c|c|c|c|c|c|c|}
\hline \multirow[b]{2}{*}{ Solved By } & \multirow{2}{*}{$\begin{array}{l}\text { Optimal cost driver } \\
\text { set }\end{array}$} & Unit pri & (\$/unit & & & \multirow[t]{2}{*}{$\begin{array}{l}\text { Budget } \\
(\$)\end{array}$} & \multirow[t]{2}{*}{$\begin{array}{l}\text { Cost } \\
\text { Savings } \\
(\$)\end{array}$} & \multirow[t]{2}{*}{$\begin{array}{l}\text { Objective } \\
\text { Function } \\
\text { (\$/unit) }\end{array}$} & \multirow[t]{2}{*}{$\begin{array}{l}\text { Absolute } \\
\text { total cost } \\
\text { deviation } \\
\text { (\$) }\end{array}$} \\
\hline & & $\mathrm{P} 1$ & $\mathrm{P} 2$ & P3 & $\mathrm{P} 4$ & & & & \\
\hline Proposed model@ @ budget $\$ 7000$ & D1, D2, D3, D6, D7 & 97.08 & 24.05 & 135.87 & 52.89 & 6500 & 4000 & 10.80 & 399.7 \\
\hline Extended model @ budget $\$ 7000$ & D1, D3, D4, D6, D7 & 106.29 & 26.40 & 114.74 & 51.74 & 6000 & 4500 & 19.54 & 382.1 \\
\hline
\end{tabular}

The two examples showed that the extended model has no advantages over the proposed model. Moreover, the budget for the solution found by the extended model is always more or equal to the budget of the solution found by the proposed model. This is why we will not adopt the extended version discussed in section 4 and we will adopt the proposed model discussed in section 3 .

\section{Conclusions}

The comparative analysis carried out in the illustration section, showed that the proposed model is effective in choosing the optimal set of cost drivers that maximizes the precision of the results that can be obtained from the activity-based costing analysis when the analysis carried out under the pressure of budget. Moreover, section 5 showed that categorizing the cost drivers into four operational expenses levels as suggested by cooper and Kaplan (1991) will not always lead to a better solution.

The superior results obtained by the proposed model relative to the results obtained from the model proposed by Babad, and Balachandran (1993); and solved by Greedy and GA methods comes as a result of two things: first, the model used in the proposed model is different than the model used in Babad, and Balachandran (1993). In the proposed model, the budget was considered as a constraint while in the Babad, and Balachandran, 1993 model there was no budget constraint, but instead, the cost savings was incorporated in the objective function. Moreover, the proposed model is concerned with one objective, which is minimizing the error in the product unit cost, while the objective function used in Babad, and Balachandran, 1993 was somehow a weighted average between two objectives: information precision and cost savings. Moreover, the way that the expenses of the removed cost drivers are handled differently in our model than the way it was handled in Babad, and Balachandran, 1993 model. Second, the method used to solve the proposed model is different; while we used Excel 2007 Solver that used the Generalized Reduced Gradient (GRG2) nonlinear optimization code to solve the model, Greedy and GA were used for comparison. This makes the conclusion about the model itself away from the method used or the conclusion about the method itself away from the model used inaccurate. Definitely we can argue that the combination of the GRG2 searching method and the proposed model used in this study together is better than the combination of the Greedy or GA searching methods and the model proposed in Babad, 
and Balachandran (1993).

Definitely, on one hand, the reliability of using Excel solver to solve the proposed model is limited by the size of the problem while Greedy or GA can handle bigger problems. One the other hand, according to a study carried by Katrin and Tajana, 2014, about $80 \%$ of the respondents in that study said that they used less or equal to 9 cost drivers in their $\mathrm{ABC}$ analysis. This means that most of the real life situations, about 10 cost drivers are adequate for carrying out $\mathrm{ABC}$ analysis. Based on that, we think that using Excel solver is adequate for most of the real life situations that involve the problem of cost driver optimization for the $\mathrm{ABC}$ analysis.

\section{Acknowledgments}

This work was supported by Applied Science Private University, Amman, Jordan [grant number DRGS-2015].

\section{References}

Alan L., \& Mahesh G., (1996). Using Genetic Algorithms to Optimize the Selection of Cost Drivers in Activity-based Costing. Intelligent Systems in Accounting, Finance and Management, 5, 129-145.

Babad, Y., \& Balachandran, B. (1993). Cost driver optimization in activity-based costing. The Accounting Review, 68(3), 563-575.

Baird, K. M., Harrison, G. L., \& Reeve, R. C. (2004). Adoption of activity management practices: a note on the extent of adoption and the influence on organizational and cultural factors. Management Accounting Research, 15, 323-399. http://dx.doi.org/10.1016/j.mar.2004.07.002

Banker, R. D., Potter, G., \& Schroeder, R. G. (1995). An Empirical Analysis of Manufacturing Overhead Cost $\begin{array}{lllll}\text { Drivers. Journal of Accounting and Economics, } & 19, & 115-137 .\end{array}$ http://dx.doi.org/10.1016/0165-4101(94)00372-C

Brignall, S. (1997). A contingent rationale for cost system design in service. Management Accounting Research, 8, 325-346. http://dx.doi.org/10.1006/mare.1996.0049

Casten H. (2001). A note on optimal cost driver selection in ABC. Management Accounting Research, 12, 197-205. http://dx.doi.org/10.1006/mare.2000.0150

Cokins, G., \& Căpuşneanu, S. (2010). Cost Drivers. Evolution and Benefits. Theoretical and Applied Economics, 8(549), 7-16.

Cooper, R., \& Kaplan, R. (1991). Profit Priorities from Activity-Based Costing. Harvard Business Review, 69, $130-135$.

Cooper, R. (1989). The rise of activity-based costing — Part Three: How many cost drivers do you need, and how do you select them? Journal of Cost Management, 2(4), 34-46.

Datar, S. M., Kekre, S., Mukhopadhyay, T., \& Srinivasan, K. (1993). Simultaneous Estimation of Cost Drivers. The Accounting Review, 68, 602-614.

Duh, Rong-Ruey, Thomas, W. L., Wang, W. Y., \& Huang, C. H. (2009). The Design and Implementation of Activity-Based Costing in a Textile Company in Taiwan. Working Paper. Marshall School of Business, University of Southern California, USA.

Foster, G., \& Swenson, D. W. (1997). Measuring the success of activity-based cost management and its determinants. Journal of Management Accounting Researchm, 109-141.

Geri, N., \& Ronen, B. (2005). Relevance lost: the rise and fall of activity-based costing. Human Systems Management, 24(2), 133-144.

Katrin, T., \& Tatjana, P. (2014). Theoretical framework and an overview of the cost drivers that are applied in universities for allocating indirect costs. Procedia-Social and Behavior Sciences, 110, 1014-1022. http://dx.doi.org/10.1016/j.sbspro.2013.12.948

Levitan, A., \& Gupta, M. (1996). Using Genetic Algorithms to Optimize the Selection of Cost Drivers in Activity-based Costing. Intelligent Systems in Accounting, Finance and Management, 5, 129-145. http://dx.doi.org/10.1002/(SICI)1099-1174(199609)5:3<129::AID-ISAF105>3.3.CO;2-J

McGowan, A., \& Klammer, T. (1997). Satisfaction with activity-based cost management implementation. Journal of Management Accounting Research, 9(Fall), 217-238.

Oduoza, C. F. (2009). Reflections on costing, pricing and income measurement at UK higher education Institutions. Journal of Higher Education Policy \& Management, 31(2), 133-147. 
http://dx.doi.org/10.1080/13600800802559328

Smith, V., \& Leksan, P. (1991). A manufacturing case study on activity-based costing. Journal of Cost Management, 5(2), 45-57.

Wang, P., Du, F., Lei, D., \& Lin, T. (2010). The Choice of Cost Drivers in Activity-Based Costing: Application at a Chinese Oil Well Cementing Company. International Journal of Management, 27(2), 367-380.

\section{Copyrights}

Copyright for this article is retained by the author(s), with first publication rights granted to the journal.

This is an open-access article distributed under the terms and conditions of the Creative Commons Attribution license (http://creativecommons.org/licenses/by/3.0/). 